\title{
Clinical predictors of pathological good response in locally advanced rectal cancer
}

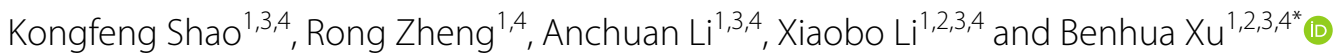

\begin{abstract}
Purpose: The aim of this study was to identify the clinical predictors of pathological good response (PGR) after neoadjuvant chemoradiotherapy (nCRT) in locally advanced rectal cancer (LARC) to clarify the indications for local excision.

Methods and materials: A total of 173 patients with LARC (CT3-4/N +) who were treated with $n C R T$ followed by surgery were enrolled in our retrospective study. Patients were categorized into two groups according to the different tumor responses of surgical pathology. Stage ypT0-1N0 was defined as the group with PGR, and stage ypT2$4 \mathrm{NO} / \mathrm{ypTanyN}+$ was the defined as the pathological poor response (PPR) group, and the potential predictors were compared.
\end{abstract}

Results: Of 173 patients, PGR was achieved in 57 patients (32.95\%). The distance from the inferior margin of the tumor to the anal verge, CT classification, pretreatment carcinoembryonic antigen (CEA) and the interval from the end of radiation to surgery were correlated with pathological response. In the multivariate analysis, the distance from anal verge $<5 \mathrm{~cm}(O R=0.443, p=0.019)$, pretreatment $C E A<5 \mathrm{ng} / \mathrm{mL}(O R=0.412, p=0.015)$ and the interval from the end of radiation to surgery $\geq 84$ days $(O R=2.652, p=0.005)$ were independent predictors of $P G R$.

Conclusions: The distance from the inferior margin of the tumor to the anal verge, pretreatment CEA and the interval from the end of radiation to surgery were significant predictors of PGR in LARC. A prospective study is needed to further validate these results in the future.

Keywords: Locally advanced rectal cancer, ypT0-1N0, Pathological good response, Predictors

\section{Introduction}

Since the results of the phase III clinical trial (CAO/ARO/ AIO-94) comparing the timing of concurrent chemoradiotherapy were published [1], preoperative fluorouracilbased neoadjuvant chemoradiotherapy (nCRT) followed by total mesorectal excision (TME) combined with postoperative adjuvant chemotherapy has become the standard treatment for locally advanced rectal cancer (LARC).

\footnotetext{
*Correspondence: benhuaxu@sina.com

1 Department of Radiation Oncology, Fujian Medical University Union Hospital, No.29 Xinquan Road, Gulou District, Fuzhou 350001, People's Republic of China

Full list of author information is available at the end of the article
}

Radical surgery may cause morbidity and various forms of functional impairment, such as defecation [2, 3], urinary [4] and sexual dysfunction [5]. At the same time, some surgeons selected local excision (LE) rather than TME for patients who responded well to nCRT to preserve organs and improve the quality of life after operation. A retrospective multicenter study reported that patients with LE alone had a better quality of life and bowel function than those who underwent TME or LE followed by TME [6]. The CARTS study also found an improved emotional functioning score for patients undergoing transanal endoscopic microsurgery according to the QLQ-C30 questionnaire [7].

Additionally, it has been reported that LE could provide acceptable oncological outcomes among 
individuals who responded well to nCRT. A phase II multicenter trial in Italy showed that LE is a good option for patients with a major clinical response after nCRT, and the 3-year overall survival (OS), diseasefree survival (DFS), and local disease-free survival were $91.5 \%, 91.0 \%$ and $96.9 \%$, respectively [8]. A propensity score analysis used ypT0-1 rectal cancer to match groups (LE:TME $=1: 1$ ) and found that LE did not increase the tumor recurrence rate compared with TME ( $4.8 \%$ vs $7.14 \%, \mathrm{p}=0.646)$, and the two groups had similar 5-year OS $(96.6 \%$ vs $88.0 \%, \mathrm{p}=0.238)$ and DFS $(95.2 \%$ vs $91.6 \%, \mathrm{p}=0.33)$ [9]. However, patients with stage ypT2 turned out to have high risk of local failure and poor survival when treated with LE; therefore, it cannot be justified as an indication for LE [10-12].

Consequently, identifying LARC patients with stage ypT0-1N0 disease before surgery is of great clinical significance. However, there are still limitations in terms of ways to evaluate the extent of primary tumor regression after nCRT, as both magnetic resonance imaging (MRI) and endoscopy show high specificity but poor sensitivity $[13,14]$. The GRECCAR 2 trial assessed tumor regression by digital rectal examination, enteroscopy and MRI, and with thorough preoperative examination, one-third of patients still had ypT2-3/R1 tumors and underwent salvage TME surgery, which increased morbidity and side effects more than those who had LE alone $(\mathrm{p}=0.0001)$ [15]. Moreover, stage ypNO affects the clinical decision-making of LE, and existing assessment methods have difficulty providing accurate regional lymph node involvement $[16,17]$.

Therefore, it is expected to identify the clinical predictors of stage ypT0-1N0 in LARC in addition to routine examinations to clarify the indications for LE, thus preserving rectal and adjacent organ function.

\section{Methods and materials Patients}

This study retrospectively analyzed a total of 173 patients with LARC who were treated with nCRT followed by surgery at our institution between August 2018 and October 2019. The inclusion criteria were as follows: (1) pathologically confirmed rectal adenocarcinoma; (2) stage IIIII (cT3-4/N+) by MRI or computed tomography (CT) combined with endorectal ultrasound according to the eighth edition of the American Joint Committee on Cancer (AJCC) Staging Manual; (3) no history of either prior surgery, pelvic radiotherapy or systematic chemotherapy; and (4) Eastern Collaborative Oncology Group (ECOG) performance status score of $0-1$ and no other serious complications. Patients with other malignant tumors were excluded.

\section{Neoadjuvant chemoradiotherapy}

Two chemotherapeutic regimens with dosages were given as follows: (1) Capox: oxaliplatin $130 \mathrm{mg} / \mathrm{m}^{2}$ intravenously guttae day 1 , capecitabine $825 \mathrm{mg} / \mathrm{m}^{2}$ twice daily oral days 1-14, every 3 weeks, for 2 cycles during concurrent radiotherapy; another 2 cycles were performed during the interval from the end of radiation to surgery; (2) capecitabine alone: capecitabine $825 \mathrm{mg} / \mathrm{m}^{2}$ twice daily oral, during the whole period of radiotherapy; another 1 cycle increased dosages to $1250 \mathrm{mg} / \mathrm{m}^{2}$ was performed in 2 weeks during the waiting period.

The gross tumor volume (GTV) was calculated based on clinical information, including digital rectal examination, endoscopy ultrasound, and abdominopelvic MRI. The clinical target volume (CTV) included all mesorectum, presacral soft tissue, obturator and internal iliac lymphatic drainage regions. The planning target volume (PTV) was defined as the GTV or CTV with uniform margins of $10 \mathrm{~mm}$. The neoadjuvant radiotherapy regimens consisted of 3-dimensional conformal radiotherapy (3D-CRT) and intensity-modulated radiation therapy (IMRT). A dose of 50.4 Gy was delivered to PTV-GTV with 3D-CRT in 28 fractions, while 50 Gy was delivered with IMRT in 25 fractions. 45 Gy was delivered to PTVCTV in 25 fractions for both types of regimens.

\section{Surgery and pathology}

Surgery was performed strictly according to the principle of TME by experienced surgeons. Patients with a good tumor response after nCRT underwent LE if they so desired. The types of surgical procedures included Miles, Dixon, Hartmann and LE. Pathological complete response (pCR) was defined as no residual tumor cells in the resected specimens, including lymph nodes, under a microscope (ypT0N0).

\section{Efficacy evaluation}

In this study, downstaging was defined as a pathological stage lower than the clinical stage by pretreatment imaging evaluation. Patients were categorized into two groups according to the different tumor responses of surgical pathology: stage ypT0-1N0 was defined as the group with pathological good response (PGR), and stage ypT2$4 \mathrm{~N} 0 / \mathrm{yp} T a n y \mathrm{~N}+$ was the pathological poor response (PPR) group. The following potential predictors were evaluated: gender, age, distance from the inferior margin of the tumor to the anal verge, clinical and pathologic TNM stage, levels of carcinoembryonic antigen (CEA) and carbohydrate antigen 199 (CA199), circumferential resection margin (CRM), extramural vascular invasion (EMVI), type of chemotherapy, interval from the end of radiation to surgery and surgical approach. 


\section{Data analysis}

Descriptive statistics are reported as the median and range. The association between different tumor responses and clinicopathological parameters was evaluated using the Pearson Chi-square test or Fisher exact test. Characteristic parameters with a $p$ value $<0.050$ were selected as potentially relevant predictor variables and were entered into a multivariable logistic regression analysis for PGR by using the backward method, and the receiver operating characteristic (ROC) curve was generated to evaluate the efficacy of the model. A $p$ value $<0.050$ was considered statistically significant. All the data were analyzed with SPSS 22.0 (SPSS Inc., Chicago, IL, USA).

\section{Results}

\section{Patients' characteristics}

A total of 173 patients with LARC who were treated with nCRT followed by surgery were enrolled; 103 patients were male, and 70 patients were female, with a median age of 56 (range 24-79 years). The median distance from the anal verge was $5.3 \mathrm{~cm}$ (range $1-13.2 \mathrm{~cm}$ ), and the median interval from the end of radiation to surgery was 78 days (range 46-227 days). Baseline characteristics are detailed in Table 1.

\section{Postoperative pathological features}

The rates of ypT downstaging, ypN downstaging and yp total stage downstaging were $80.35 \%, 83.82 \%$ and $73.41 \%$, respectively. There were 47 patients $(27.17 \%)$ who achieved pCR. Furthermore, 57 patients (32.95\%) achieved PGR, while 116 patients $(67.05 \%)$ achieved PPR. The rate of R0 resection was $99.42 \%$, only one case showed microscopic residual tumor at the lower margin, and the rate of anal preservation was $93.06 \%$ (Table 2).

\section{Characteristic parameters with tumor response}

The distance from the inferior margin of the tumor to the anal verge $(p=0.007)$, cT classification $(p<0.001)$, levels of pretreatment CEA $(\mathrm{p}=0.006)$, and the interval from the end of radiation to surgery $(p=0.002)$ were significantly correlated with tumor response in the univariate Chi-square analysis when excluding $\mathrm{cN}$ classification, chemotherapeutic regimens, imaging features and the types of surgical procedures (Table 3 ).

\section{Clinical predictors and predictive model of PGR}

Backward selection was employed to exclude the cT classification with no bearing on significance. A distance from the anal verge $<5 \mathrm{~cm}(\mathrm{OR}=0.443, \mathrm{p}=0.019)$, pretreatment $\mathrm{CEA}<5 \mathrm{ng} / \mathrm{mL}(\mathrm{OR}=0.412, \mathrm{p}=0.015)$ and an interval from the end of radiation to surgery $\geq 84$ days $(\mathrm{OR}=2.652, \mathrm{p}=0.005)$ were considered as clinical predictors of PGR (Table 4).
Table1 Characteristics of locally advanced rectal cancer patients

\begin{tabular}{|c|c|}
\hline Characteristics values & Counts \\
\hline \multicolumn{2}{|l|}{ Gender } \\
\hline Male & 103 \\
\hline Female & 70 \\
\hline Age (years, median [range]) & $56(24-79)$ \\
\hline The distance from anal verge ( $\mathrm{cm}$, median [range]) & $5.3(1-13.2)$ \\
\hline \multicolumn{2}{|l|}{ cT classification } \\
\hline 2 & 10 \\
\hline 3 & 69 \\
\hline 4 & 94 \\
\hline \multicolumn{2}{|l|}{ cN classification } \\
\hline 0 & 7 \\
\hline 1 & 44 \\
\hline 2 & 122 \\
\hline \multicolumn{2}{|l|}{ Clinical stage } \\
\hline$\|$ & 7 \\
\hline III & 166 \\
\hline Pretreatment CEA (ng/mL, median [range]) & $4(0.6-306.6)$ \\
\hline Pretreatment CA199 (U/mL, median [range]) & $13.01(0.75-1000)$ \\
\hline Posttreatment CEA (ng/mL, median [range]) & $2.5(0.6-71.8)$ \\
\hline Posttreatment CA199 (U/mL, median [range]) & $11.66(0-107.2)$ \\
\hline \multicolumn{2}{|l|}{ Concurrent chemotherapy } \\
\hline Capecitabine & 78 \\
\hline Capox & 95 \\
\hline \multicolumn{2}{|l|}{ CRM } \\
\hline Positive & 80 \\
\hline Negative & 93 \\
\hline \multicolumn{2}{|l|}{ EMVI } \\
\hline Positive & 86 \\
\hline Negative & 87 \\
\hline $\begin{array}{l}\text { The neoadjuvant-surgery interval (day, median } \\
\text { [range]) }\end{array}$ & $78(46-227)$ \\
\hline \multicolumn{2}{|l|}{ The types of surgical procedures } \\
\hline Dixon & 152 \\
\hline Miles & 10 \\
\hline Hartmann & 2 \\
\hline Local excision & 9 \\
\hline
\end{tabular}

Clinical TNM stage, according to the eighth edition of the AJCC staging manual CEA carcinoembryonic antigen, CA199 carbohydrate antigen 199, CRM circumferential resection margin, EMVI extramural vascular invasion

Taking tumor response as the variable of state, the results of the logistic regression model in Table 4 were assessed. The area under the curve (AUC) was 0.702, which indicates moderate discriminative ability in this model (Fig. 1). 
Table 2 Postoperative pathological features

\begin{tabular}{|c|c|}
\hline Pathological characteristics & Counts \\
\hline \multicolumn{2}{|l|}{ ypT classification } \\
\hline 0 & 48 \\
\hline 1 & 11 \\
\hline 2 & 39 \\
\hline 3 & 71 \\
\hline 4 & 4 \\
\hline \multicolumn{2}{|l|}{ ypN classification } \\
\hline 0 & 129 \\
\hline 1 & 32 \\
\hline 2 & 12 \\
\hline \multicolumn{2}{|c|}{ T classification downstaging (cT>ypT) } \\
\hline Yes & 139 \\
\hline No & 34 \\
\hline \multicolumn{2}{|c|}{ N classification downstaging (cN > ypN) } \\
\hline Yes & 145 \\
\hline No & 28 \\
\hline \multicolumn{2}{|c|}{ Total stage downstaging (cStage > ypStage) } \\
\hline Yes & 127 \\
\hline No & 46 \\
\hline \multicolumn{2}{|l|}{ Pathological stage } \\
\hline pCR (ypTONO) & 47 \\
\hline 1 & 43 \\
\hline$\|$ & 39 \\
\hline III & 44 \\
\hline \multicolumn{2}{|l|}{ Tumor response } \\
\hline Stage ypT0-1N0 & 57 \\
\hline Stage ypT2-4N0/ypTanyN + & 116 \\
\hline \multicolumn{2}{|l|}{ Surgical margin } \\
\hline RO & 172 \\
\hline $\mathrm{R} 1$ & 1 \\
\hline \multicolumn{2}{|l|}{ Anal preservation } \\
\hline Yes & 161 \\
\hline No & 12 \\
\hline
\end{tabular}

Pathological TNM stage, according to the eighth edition of the AJCC staging manual

$p C R$ pathological complete response

\section{Risk factors for PGR}

Based on the above results, a distance from the inferior margin of the tumor to the anal verge $\geq 5 \mathrm{~cm}$, pretreatment $C E A \geq 5 \mathrm{ng} / \mathrm{mL}$ and an interval from the end of radiation to surgery $<84$ days were recorded as three risk factors for poor tumor response. The proportions of PGR in the corresponding population with different risk factors were as follows: no risk factor, $76.19 \%(16 / 21) ; 1$ factor, $35.59 \%$ (21/59); 2 factors, $25.81 \%$ (16/62); and 3 factors, $12.90 \%(4 / 31)(\mathrm{p}<0.001)$. The proportion of PGR in patients without risk factors was significantly higher than that in all others with at least one risk factor (Fig. 2).

\section{Discussion}

With the development of surgical technology, patients with early rectal cancer who underwent LE were found to have no significant difference in survival compared with those treated with TME $[18,19]$. This finding was also confirmed in patients with LARC who responded well to nCRT [8-10]. Therefore, this study used clinical data to screen out the relevant predictors of stage ypT0-1N0 after $\mathrm{nCRT}$ in LARC to guide individualized treatment strategies.

A retrospective study of 562 patients demonstrated that a distance from the anal verge $>5 \mathrm{~cm}$ was associated with a lower tumor downstaging rate [20]. Proximity to the anal verge is one of the favorable predictors for tumor response in another large retrospective cohort [21]. Moreover, our results indicated that a distance from the anal verge $<5 \mathrm{~cm}$ was a predictor for stage ypT0-1N0 in the multivariable analysis. Conversely, Han's research [22] found that a moderate tumor distance $(6-10 \mathrm{~cm})$ was an independent predictive factor for pCR; other studies have also reported similar results [23, 24]. Different tumor locations showed divergent responses in patients with LARC who were treated with nCRT. The association of tumor location and response to chemoradiation is also unclear. The possible explanations were that lower tumors could receive a better treatment dose due to the fixed position, and concerns with small bowel toxicity in higher tumors could affect treatment planning.

CEA is one of the most widely used and readily available tumor markers for the management of colorectal cancer. Probst et al. [25] screened out 18,113 patients with LARC by selecting from the 2006-2011 National Cancer Data Base, $47 \%$ had elevated pretreatment CEA which was significantly associated with decreased pCR $(\mathrm{OR}=0.65, \mathrm{p}<0.001)$, pathological tumor regression $(\mathrm{OR}=0.74, \mathrm{p}<0.001)$ and downstaging $(\mathrm{OR}=0.77$, $\mathrm{p}<0.001)$. A CEA level $\leq 5 \mathrm{ng} / \mathrm{ml}$ was a significant predictor of downstaging $(\mathrm{OR}=16.0, \mathrm{p}=0.014)$ and was significantly associated with downsizing $(>60 \%, \mathrm{p}=0.012)$ in Yeo's study results [26]. A case-matched control study of KROG 14-12 [27] also reported that pretreatment $\mathrm{CEA}>5 \mathrm{ng} / \mathrm{mL}$ is a negative predictor of tumor downstaging. This is also consistent with our results, which supported that pretreatment $\mathrm{CEA}<5 \mathrm{ng} / \mathrm{mL}$ could be a considerable clinical predictor of stage ypT0-1N0 in LARC.

Investigations regarding the best interval from the end of radiation to surgery began to appear as early as the 1990s, the most famous of which was the Lyon R90-01 randomized trial [28]. It was generally accepted that the interval should be extended to 6-8 weeks due to the long interval group that showed a better pathologic response. Another phase II clinical trial to investigate extending 
Table 3 Characteristic parameters with tumor response

\begin{tabular}{|c|c|c|c|c|}
\hline \multirow[t]{2}{*}{ Variables } & \multirow[t]{2}{*}{ Classification } & \multicolumn{2}{|c|}{ Tumor response } & \multirow[t]{2}{*}{$\mathrm{p}$} \\
\hline & & урт0-1No & урT2-4N0/ypTanyN + & \\
\hline \multirow[t]{3}{*}{ Gender } & & & & 0.523 \\
\hline & Male & 32 & 71 & \\
\hline & Female & 25 & 45 & \\
\hline \multirow[t]{3}{*}{ Age (years) } & & & & 0.237 \\
\hline & $<60$ & 29 & 70 & \\
\hline & $\geq 60$ & 28 & 46 & \\
\hline \multirow[t]{3}{*}{ The distance from anal verge $(\mathrm{cm})$} & & & & 0.007 \\
\hline & $<5$ & 33 & 42 & \\
\hline & $\geq 5$ & 24 & 74 & \\
\hline \multirow[t]{4}{*}{ CT classification } & & & & $<0.001$ \\
\hline & 2 & 9 & 1 & \\
\hline & 3 & 16 & 53 & \\
\hline & 4 & 32 & 62 & \\
\hline \multirow[t]{4}{*}{ cN classification } & & & & 0.513 \\
\hline & 0 & 3 & 4 & \\
\hline & 1 & 17 & 27 & \\
\hline & 2 & 37 & 85 & \\
\hline \multirow[t]{3}{*}{ Clinical stage } & & & & 0.874 \\
\hline & $\|$ & 3 & 4 & \\
\hline & III & 54 & 112 & \\
\hline \multirow[t]{3}{*}{ Pretreatment CEA (ng/mL) } & & & & 0.006 \\
\hline & $<5$ & 41 & 58 & \\
\hline & $\geq 5$ & 16 & 58 & \\
\hline \multirow[t]{3}{*}{ Posttreatment CA199 (U/mL) } & & & & 0.799 \\
\hline & $<37$ & 52 & 106 & \\
\hline & $\geq 37$ & 5 & 10 & \\
\hline \multirow[t]{3}{*}{ Pretreatment CEA (ng/mL) } & & & & 0.690 \\
\hline & $<5$ & 49 & 97 & \\
\hline & $\geq 5$ & 8 & 19 & \\
\hline \multirow[t]{3}{*}{ Posttreatment CA199 (U/mL) } & & & & 0.735 \\
\hline & $<37$ & 54 & 110 & \\
\hline & $\geq 37$ & 3 & 6 & \\
\hline \multirow[t]{3}{*}{ Concurrent chemotherapy } & & & & 0.127 \\
\hline & Capecitabine & 21 & 57 & \\
\hline & Capox & 36 & 59 & \\
\hline \multirow[t]{3}{*}{ CRM } & & & & 0.594 \\
\hline & Positive & 28 & 52 & \\
\hline & Negative & 29 & 64 & \\
\hline \multirow[t]{3}{*}{ EMVI } & & & & 0.450 \\
\hline & Positive & 26 & 60 & \\
\hline & Negative & 31 & 56 & \\
\hline \multirow[t]{3}{*}{ The neoadjuvant-surgery interval (day) } & & & & 0.002 \\
\hline & $<84$ & 25 & 79 & \\
\hline & $\geq 84$ & 32 & 37 & \\
\hline \multirow[t]{3}{*}{ The types of surgical procedures } & & & & 0.303 \\
\hline & Dixon & 48 & 104 & \\
\hline & Others & 9 & 12 & \\
\hline
\end{tabular}

Clinical TNM stage, according to the eighth edition of the AJCC staging manual

CEA carcinoembryonic antigen, CA199 carbohydrate antigen 199, CRM circumferential resection margin, EMVI extramural vascular invasion 
the interval and administering additional mFOLFOX-6 during the waiting period found that the 11-week group showed a modest increase in the pCR rate without increasing complications [29]. When the mean interval time reached 19.3 weeks, the $\mathrm{pCR}$ rate was as high as $38 \%$
[30]. However, it did not seem to obviously improve the tumor response as the interval time increased blindly. Rombouts et al. [31] retrieved 1073 LARC patients from the population-based Netherlands Cancer Registry between 2006 and 2011, and the highest proportion of

Table 4 Logistic regression analysis with stage ypTO-1NO as dependent variable

\begin{tabular}{lllll}
\hline Variables & Regression coefficient & SE & p value & Odds ratio (95\%Cl) \\
\hline The distance from anal verge & -0.813 & 0.346 & 0.019 & $0.443(0.225-0.873)$ \\
Pretreatment CEA & -0.887 & 0.363 & 0.015 & $0.412(0.202-0.84)$ \\
The neoadjuvant-surgery interval & 0.975 & 0.347 & 0.005 & $2.652(1.345-5.23)$ \\
Constant & -0.365 & & \\
\hline
\end{tabular}

SE standard error, $\mathrm{Cl}$ confidence interval, CEA carcinoembryonic antigen

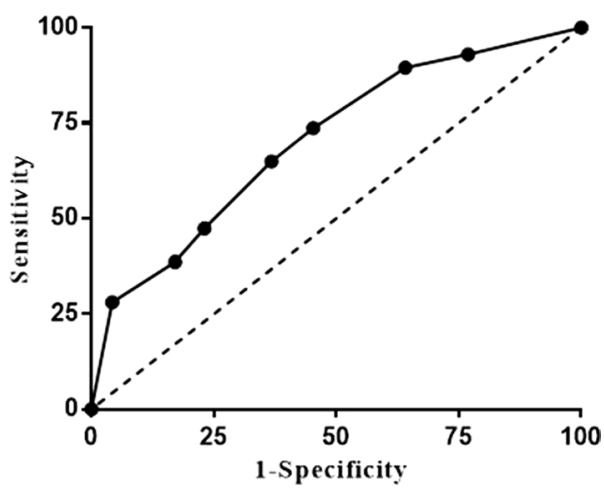

Fig. 1 The receiver operating characteristic curve was generated to evaluate the logistic regression model, and the area under the curve was 0.702 , which indicates moderate discriminative performance of this predictive model

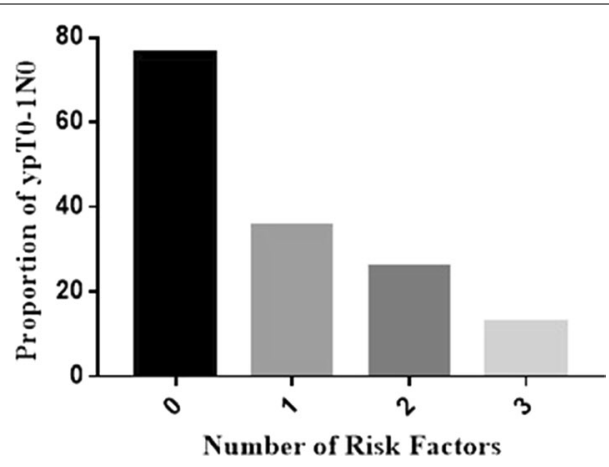

Fig. 2 The proportions of stage ypT0-1N0 peaked at 76.19\% with no risk factors, which included a distance from the anal verge $\geq 5 \mathrm{~cm}$, pretreatment CEA $\geq 5 \mathrm{ng} / \mathrm{mL}$ and the neoadjuvant-surgery interval $<84$ days, followed by a downward trend with increased risk factors patients with stage ypT0-1N0 was $26.6 \%$ when the treatment interval ranged from 11-12 weeks. Sloothaak et al. [32] also observed that the proportion of stage ypT0$1 \mathrm{~N} 0$ peaked at $23.2 \%$ with $10-11$ week intervals, followed by a downward trend. Interestingly, our study proved that an interval $\geq 84$ days $(O R=2.652, p=0.005)$ was an independent predictor of stage ypT0-1N0, and there were no significant differences in the quality of surgery or postoperative complications over time.

It is worth noting that a variety of preoperative examinations, such as digital rectal examination, endoscopy and pelvic MRI, can be used to rigorously assess the primary tumor response. In particular, the preoperative diagnosis of the status of regional lymph nodes is extremely dependent on imaging. Kim et al. [33] found that the probability of lymph node metastasis was correlated with ypT classification. Positive lymph nodes were detected in $3.4 \%$ of ypT0-1 patients, $16.9 \%$ of ypT2 patients, $49.3 \%$ of ypT3 patients and $42.9 \%$ of ypT4 patients. Our findings also supported Kim's idea; namely, positive lymph nodes were detected in 2 of 51 (3.92\%) ypT0-1 patients and in 6 of $38(15.79 \%)$ ypT2 patients. It was considered that lymph node metastasis was rare in ypT0-1 patients. In addition, 18-FDG-positron-emission tomography integrated with computed tomography (18-FDG-PET/CT) could prompt a higher metabolic profile of disease in the worse tumor regression [34], which could be useful to guide the choice of LE in LARC.

Previously a multicentric study in Italy indicated that radiation dose intensification (range 52.5-57.5 Gy) appeared feasible, safe and effective in terms of pathological response [35]. Of which people that underwent LE, a month later, did not report any postoperative complications. More recently, a prospective observational study mentioned that radiation dose intensification, delivered 60 Gy in 30 fractions, showed a better pathologic response with acceptable toxicity related to nCRT in T3 
tumors [36]. A longer follow-up period is warranted. Notably, some potential factors may provide a higher likelihood for the choice of LE in LARC and deserve further investigation.

Nevertheless, there are still some limitations in our study. First, the data were derived from a single institution, and insufficient samples may lead to the failure of some clinically related factors, such as cT classification, to show significant differences. Second, the characteristic parameters included were not comprehensive enough, which may lead to a decrease in the efficiency of the model. Finally, we used a multivariable logistic regression model but lacked an independent validation cohort to confirm the value of the above predictors. Further studies should expand the sample and introduce more variables to improve the effectiveness of the model to stratify and guide patients for individualized treatment strategies, especially for LE management after nCRT in LARC.

\section{Conclusion}

In our retrospective study, a distance from the inferior margin of the tumor to the anal verge $<5 \mathrm{~cm}$, pretreatment $C E A<5 \mathrm{ng} / \mathrm{mL}$ and the interval from the end of radiation to surgery $\geq 84$ days were independent predictors of stage ypT0-1N0 after nCRT in LARC.

\section{Acknowledgements}

We would like to acknowledge the work of Benhua Xu, which remarkably improved the quality of this paper.

\section{Authors' contributions}

KS: Data collection, statistics, original draft. RZ, AL, XL: Review and editing the manuscript. BX: Conception and design. All authors read and approved the final manuscript.

\section{Funding}

This work was supported by the Joint Funds for the innovation of science and Technology, Fujian province (Grant Number: 2017Y9061).

Availability of supporting data The data used to support the findings of this study are available from the corresponding author upon request.

\section{Ethical approval and consent to participate}

Although patient consent was not specifically obtained for this analysis, all information was retrospectively extracted in the context of compliance with the ethical standards of the institutional and/or national research committees and with the principles of the 1964 Declaration of Helsinki and its later amendments or comparable ethical standards. Patient medical records were analyzed retrospectively, with no individual patient identifiable information used. Thus, the Fujian Medical University Union Hospital Ethics Review Board deemed patient consent unnecessary.

\section{Consent for publication}

The manuscript has been approved by all authors for publication.

\section{Competing interests}

All authors have no conflicts of interest to declare.

\section{Author details}

${ }^{1}$ Department of Radiation Oncology, Fujian Medical University Union Hospital, No.29 Xinquan Road, Gulou District, Fuzhou 350001, People's Republic of China. ${ }^{2}$ College of Medical Technology and Engineering, Fujian Medical University, Fuzhou, People's Republic of China. ${ }^{3}$ School of Clinical Medicine, Fujian Medical University, Fuzhou, People's Republic of China. ${ }^{4}$ College of Union Clinical Medicine, Fujian Medical University, Fuzhou, People's Republic of China.

Received: 12 November 2020 Accepted: 26 December 2020 Published online: 13 January 2021

\section{References}

1. Sauer R, Becker H, Hohenberger W, Rödel C, Wittekind C, Fietkau R, Martus P, Tschmelitsch J, Hager E, Hess CF, et al. Preoperative versus postoperative chemoradiotherapy for rectal cancer. N Engl J Med. 2004;351:1731-40.

2. Emmertsen KJ, Laurberg S. Impact of bowel dysfunction on quality of life after sphincter-preserving resection for rectal cancer. Br J Surg. 2013;100:1377-87.

3. den Dulk M, Smit M, Peeters KCMJ. Kranenbarg EM-K, Rutten HJT, Wiggers T, Putter $\mathrm{H}$, van de Velde $\mathrm{CJH}$ : A multivariate analysis of limiting factors for stoma reversal in patients with rectal cancer entered into the total mesorectal excision (TME) trial: a retrospective study. Lancet Oncol. 2007:8:297-303.

4. Karlsson L, Bock D, Asplund D, Ohlsson B, Rosenberg J, Angenete E. Urinary dysfunction in patients with rectal cancer: a prospective cohort study. Colorectal Dis. 2020;22:18-28.

5. Sörensson M, Asplund D, Matthiessen P, Rosenberg J, Hallgren T, Rosander C, González E, Bock D, Angenete E. Self-reported sexual dysfunction in patients with rectal cancer. Colorectal Dis. 2020;22(5):500-12.

6. Pucciarelli S, Giandomenico F, De Paoli A, Gavaruzzi T, Lotto L, Mantello G, Barba C, Zotti P, Flora S, Del Bianco P. Bowel function and quality of life after local excision or total mesorectal excision following chemoradiotherapy for rectal cancer. BJS (Br J Surg). 2017;104:138-47.

7. Stijns RCH, de Graaf EJR, Punt CJA, Nagtegaal ID, Nuyttens JJME, van Meerten E, Tanis PJ, de Hingh IHJT, van der Schelling GP, Acherman Y, et al. Long-term oncological and functional outcomes of chemoradiotherapy followed by organ-sparing transanal endoscopic microsurgery for distal rectal cancer: the CARTS Study. JAMA Surg. 2019;154:47-54.

8. Pucciarelli S, De Paoli A, Guerrieri M, La Torre G, Maretto I, De Marchi F, Mantello G, Gambacorta MA, Canzonieri V, Nitti D, et al. Local excision after preoperative chemoradiotherapy for rectal cancer: results of a multicenter phase II clinical trial. Dis Colon Rectum. 2013;56:1349-56.

9. Jung SM, Yu CS, Park IJ, Kim TW, Kim JH, Yoon YS, Lim S-B, Kim JC. Oncologic safety of local excision compared with total mesorectal excision for ypT0-T1 rectal cancer: a propensity score analysis. Medicine. 2016;95:e3718

10. Borschitz T, Wachtlin D, Möhler M, Schmidberger H, Junginger T. Neoadjuvant chemoradiation and local excision for T2-3 rectal cancer. Ann Surg Oncol. 2008;15:712-20.

11. Perez RO, Habr-Gama A, Lynn PB, São Julião GP, Bianchi R, Proscurshim I, Gama-Rodrigues J. Transanal endoscopic microsurgery for residual rectal cancer (ypT0-2) following neoadjuvant chemoradiation therapy: another word of caution. Dis Colon Rectum. 2013;56(1):6-13.

12. Yang KM, Lim S-B, Lee JL, Kim CW, Yoon YS, Park IJ, Yu CS, Kim JC. Local excision for ypT2 rectal cancer following preoperative chemoradiation therapy: it should not be justified. Int J Colorectal Dis. 2018;33:487-91.

13. Jang JK, Choi SH, Park SH, Kim KW, Kim HJ, Lee JS, Kim AY. MR tumor regression grade for pathological complete response in rectal cancer post neoadjuvant chemoradiotherapy: a systematic review and metaanalysis for accuracy. Eur Radiol. 2020;30:2312-23. 
14. Han KS, Sohn DK, Kim DY, Kim BC, Hong CW, Chang HJ, Kim SY, Baek JY, Park SC, Kim MJ, Oh JH. Endoscopic criteria for evaluating tumor stage after preoperative chemoradiation therapy in locally advanced rectal cancer. Cancer Res Treat. 2016;48:567-73.

15. Rullier E, Rouanet $P$, Tuech J-J, Valverde A, Lelong B, Rivoire M, Faucheron J-L, Jafari M, Portier G, Meunier B, et al. Organ preservation for rectal cancer (GRECCAR 2): a prospective, randomised, open-label, multicentre, phase 3 trial. The Lancet. 2017;390:469-79.

16. Li XT, Sun YS, Tang L, Cao K, Zhang XY. Evaluating local lymph node metastasis with magnetic resonance imaging, endoluminal ultrasound and computed tomography in rectal cancer: a meta-analysis. Colorectal Dis. 2015;17:0129-35.

17. Gao Y, Li J, Ma X, Wang J, Wang B, Tian J, Chen G. The value of four imaging modalities in diagnosing lymph node involvement in rectal cancer: an overview and adjusted indirect comparison. Clin Exp Med. 2019;19:225-34.

18. Cao B, Min L, Zhu S, Shi H, Zhang S. Long-term oncological outcomes of local excision versus radical resection for early colorectal cancer in young patients without preoperative chemoradiotherapy: a population-based propensity matching study. Cancer Med. 2018;7:2415-22.

19. O'Neill CH, Platz J, Moore JS, Callas PW, Cataldo PA. Transanal endoscopic microsurgery for early rectal cancer: a single-center experience. Dis Colon Rectum. 2017;60:152-60.

20. Das P, Skibber JM, Rodriguez-Bigas MA, Feig BW, Chang GJ, Wolff RA, Eng C, Krishnan S, Janjan NA, Crane CH. Predictors of tumor response and downstaging in patients who receive preoperative chemoradiation for rectal cancer. Cancer. 2007;109:1750-5.

21. Armstrong D, Raissouni S, Price Hiller J, Mercer J, Powell E, MacLean A, Jiang M, Doll C, Goodwin R, Batuyong E, et al. Predictors of pathologic complete response after neoadjuvant treatment for rectal cancer: a multicenter study. Clin Colorectal Cancer. 2015;14:291-5.

22. Han YD, Kim WR, Park SW, Cho MS, Hur H, Min BS, Baik SH, Lee KY, Kim NK. Predictors of pathologic complete response in rectal cancer patients undergoing total mesorectal excision after preoperative chemoradiation. Medicine. 2015;94:e1971-e1971.

23. Restivo A, Zorcolo L, Cocco IMF, Manunza R, Margiani C, Marongiu L, Casula G. Elevated CEA levels and low distance of the tumor from the anal verge are predictors of incomplete response to chemoradiation in patients with rectal cancer. Ann Surg Oncol. 2013;20:864-71.

24. Patel SV, Roxburgh CS, Vakiani E, Shia J, Smith JJ, Temple LK, Paty P, GarciaAguilar J, Nash G, Guillem J, et al. Distance to the anal verge is associated with pathologic complete response to neoadjuvant therapy in locally advanced rectal cancer. J Surg Oncol. 2016;114:637-41.

25. Probst CP, Becerra AZ, Aquina CT, Tejani MA, Hensley BJ, González MG, Noyes K, Monson JRT, Fleming FJ. Watch and wait? Elevated pretreatment CEA is associated with decreased pathological complete response in rectal cancer. J Gastrointest Surg. 2016;20:43-52.

26. Yeo S-G. Association of pretreatment serum carcinoembryonic antigen levels with chemoradiation-induced downstaging and downsizing of rectal cancer. Mol Clin Oncol. 2016;4:631-5.
27. Lee JH, Kim DY, Kim SH, Cho HM, Shim BY, Kim TH, Kim SY, Baek JY, Oh $J \mathrm{H}, \mathrm{Nam}$ TK, et al. Carcinoembryonic antigen has prognostic value for tumor downstaging and recurrence in rectal cancer after preoperative chemoradiotherapy and curative surgery: A multi-institutional and casematched control study of KROG 14-12. Radiother Oncol. 2015;116:202-8.

28. Cotte E, Passot G, Decullier E, Maurice C, Glehen O, François Y, Lorchel F, Chapet O, Gerard J-P. Pathologic response, when increased by longer interval, is a marker but not the cause of good prognosis in rectal cancer: 17-year follow-up of the lyon R90-01 randomized trial. Int J Radiat Oncol Biol Phys. 2016;94:544-53.

29. Garcia-Aguilar J, Smith DD, Avila K, Bergsland EK, Chu P, Krieg RM. Timing of Rectal Cancer Response to Chemoradiation C: Optimal timing of surgery after chemoradiation for advanced rectal cancer: preliminary results of a multicenter, nonrandomized phase II prospective trial. Ann Surg. 2011;254:97-102.

30. Garcia-Aguilar J, Chow OS, Smith DD, Marcet JE, Cataldo PA, Varma MG, Kumar AS, Oommen S, Coutsoftides T, Hunt SR, et al. Effect of adding mFOLFOX6 after neoadjuvant chemoradiation in locally advanced rectal cancer: a multicentre, phase 2 trial. Lancet Oncol. 2015;16:957-66.

31. Rombouts AJM, Hugen N, Elferink MAG, Nagtegaal ID, de Wilt JHW. Treatment interval between neoadjuvant chemoradiotherapy and surgery in rectal cancer patients: a population-based study. Ann Surg Oncol. 2016;23:3593-601.

32. Sloothaak DAM, Geijsen DE, van Leersum NJ, Punt CJA, Buskens CJ, Bemelman WA, Tanis PJ. on behalf of the Dutch surgical colorectal a: optimal time interval between neoadjuvant chemoradiotherapy and surgery for rectal cancer. BJS (Br J Surg). 2013;100:933-9.

33. Kim D-W, Kim DY, Kim TH, Jung KH, Chang HJ, KyungSohn D, Lim S-B, Choi HS. Jeong S-y, Park J-G: Is T classification still correlated with lymph node status after preoperative chemoradiotherapy for rectal cancer? Cancer. 2006;106:1694-700.

34. Alongi F, Fersino S, Mazzola R, Fiorentino A, Giaj-Levra N, Ricchetti F, Ruggieri R, Di Paola G, Cirillo M, Gori S, et al. Radiation dose intensification in pre-operative chemo-radiotherapy for locally advanced rectal cancer. Clin Transl Oncol. 2017;19:189-96.

35. Lupattelli M, Matrone F, Gambacorta MA, Osti M, Macchia G, Palazzari E, Nicosia L, Navarria F, Chiloiro G, Valentini V, et al. Preoperative intensitymodulated radiotherapy with a simultaneous integrated boost combined with Capecitabine in locally advanced rectal cancer: short-term results of a multicentric study. Radiat Oncol. 2017;12:139.

36. Bertocchi E, Barugola G, Nicosia L, Mazzola R, Ricchetti F, Dell'Abate P, Alongi F, Ruffo $\mathrm{G}$. A comparative analysis between radiation dose intensification and conventional fractionation in neoadjuvant locally advanced rectal cancer: a monocentric prospective observational study. Radiol Med. 2020;125:990-8.

\section{Publisher's Note}

Springer Nature remains neutral with regard to jurisdictional claims in published maps and institutional affiliations.

\footnotetext{
Ready to submit your research? Choose BMC and benefit from:

- fast, convenient online submission

- thorough peer review by experienced researchers in your field

- rapid publication on acceptance

- support for research data, including large and complex data types

- gold Open Access which fosters wider collaboration and increased citations

- maximum visibility for your research: over $100 \mathrm{M}$ website views per year
}

At BMC, research is always in progress.

Learn more biomedcentral.com/submissions 